\title{
Research and determination of tartrazine in artisanal yoghurts commercialized in Abidjan (Côte d'Ivoire)
}

\author{
Christophe N'Cho Amin ", Nicaise François Bony, Gildas Komenan Gbassi, Michèle Aké \\ Département de Chimie Analytique, UFR Sciences Pharmaceutiques et Biologiques - Université Félix Houphouët-Boigny, Côte d'Ivoire
}

\section{Email address:}

amin.ncho@yahoo.fr (C. N. Amin), bonynicaise@yahoo.fr (N. F. Bony), gildas_gbassi@yahoo.fr (G. K Gbassi), dominique_ake@yahoo.fr(Michèle Aké)

\section{To cite this article:}

Christophe N'Cho Amin, Nicaise François Bony, Gildas Komenan Gbassi, Michèle Aké. Research and Determination of Tartrazine in Artisanal Yoghurts Commercialized in Abidjan (Côte d'Ivoire). International Journal of Nutrition and Food Sciences. Vol. 3, No. 2, 2014, pp. 119-122. doi: 10.11648/j.jinfs.20140302.25

\begin{abstract}
The use of tartrazine E 102 as a food dye is subject to restrictions. The limit dose allowed in dairy product is 300 $\mathrm{mg} \mathrm{kg}^{-1}$. In order to discover and control this synthetic dye in commercialized yoghurt in Côte d'Ivoire, a method has been proposed to determine its content by ion pair reversed phase liquid chromatography (LC) after liquid-solid extraction followed by detection at $430 \mathrm{~nm}$. The results of the validation tests (linearity, precision, accuracy and sensitivity) were satisfactory. The method was thus applied to 210 samples of yoghurt produced by the traditional sector and commercialized in Abidjan. The content of tartrazine was higher than the maximum allowed of $300 \mathrm{mg} \mathrm{kg}^{-1}$ in 10 (4.8\%) samples. The repeated consumption of these yoghurts can eventually cause allergic reactions and hyperactivity disorders in susceptible consumers especially in children.
\end{abstract}

Keywords: Tartrazine, Yoghurt, Liquid Chromatography, Quality Control

\section{Introduction}

The synthetic dyes which emerged since the 1850 s, have largely replaced natural additives. They are used to make or restore food coloring and therefore increase their visual appeal to the consumer [1]. Tartrazine (E 102) also called yellow tartaric acid (Figure 1) is a synthetic azo dye authorized as a food additive in some countries [2]. In these countries, it is one of the most used mainly in dairy products, derivatives and drinks [3, 4]. Its inclusion in the diet is sometimes controversial because of allergenic properties reported. Few cases of urticaria, asthma, contact dermatitis, vasculitis have been reported after consumption of food containing tartrazine [5]. Hyperactivity disorders resulting in a lack of attention in children are also reported [6]. So, to protect the health of consumers, a standard norm of $300 \mathrm{mg}$ per kg of tartrazine in dairy products and a qualifying $7.5 \mathrm{mg}$ per kg of body weight daily dose have been established [7].

To ensure the control of levels of tartrazine in food, literature reports several methods: Spectrophotometric methods [8], electrochemical methods [9-11], chromatographic methods [12-22] and immunological methods [23]. In Côte d'Ivoire, the determination of tartrazine by liquid chromatography in lemonade was made without preliminary extraction step [22]. Such results have objectified the presence of tartrazine in excess of the standard lemonade informal sector levels. In the present study, research and determination of this dye has been made in yoghurt produced and marketed in Côte d'Ivoire by liquid chromatography after liquid / solid partition extraction.

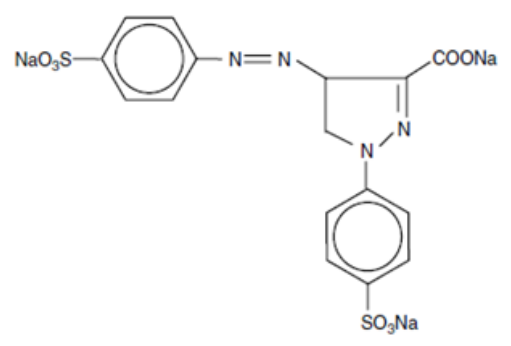

Figure 1. Chemical structure of tartrazine.

\section{Experimental}

\subsection{Chemicals and Samples}

All chemicals and solvents were of analytical grade from different suppliers. Tartrazine, HPLC grade methanol, tétrabutylammonium hydroxide were from Prolabo 
(Fontenay-sous-Bois, France). Sodium dihydrogen phosphate and silica gel were from Merck (Darmstadt, Germany). Cotton was from Euromedis (Neuilly-sous-Clermont, France).

The samples are composed of 21 independent artisanal productions (P1 to $\mathrm{P} 21$ ) with 10 sachets of yoghurt per production. These yoghurts were purchased around primary schools, health centers and markets in several municipalities in the district of Abidjan. 210 collected samples were stored in a refrigerator at a temperature between $+4{ }^{\circ} \mathrm{C}$ and $+8^{\circ} \mathrm{C}$ before analysis.

\subsection{Instrumentation and Chromatographic Conditions}

The apparatus consists of a liquid chromatograph (SHIMADZU), an extraction column of $50 \mathrm{~mL}$ glass (MERCK), a stirrer (VWR), a precision scale (METTLER TOLEDO PB 303-S) and a vacuum filtration device (MERCK). The extractive column is washed and dried. Cotton is placed in the bottom of the column and $10 \mathrm{~g}$ of silica gel were weighed and introduced therein. This preparative column is used to extract tartrazine in yoghurt sample. Tartrazine was analysed on a Nucleosil ODS (C18, 5 $\mu \mathrm{m})$ column $(100 \mathrm{~mm} \times 4.6 \mathrm{~mm})$ using a mobile phase containing methanol-dihydrogen phosphate buffer $0.005 \mathrm{M}$ $\mathrm{pH} 7.5(60: 40, \mathrm{v} / \mathrm{v})$ added to $1 \%(\mathrm{v} / \mathrm{v})$ of tetrabutylammonium hydroxide $0.005 \mathrm{M}$ as counter ion, at a flow rate of $0.8 \mathrm{~mL} \mathrm{~min}^{-1}$. Tartrazine was detected at $430 \mathrm{~nm}$ wavelength $[17,21]$.

\subsection{Sample Preparation}

\subsubsection{Preparation of Standard Solutions}

Stock solution was prepared by dissolving $10 \mathrm{mg}$ of tartrazine in $100 \mathrm{~mL}$ volumetric flask with distilled water to obtain a concentration of $100 \mathrm{mg} \mathrm{L}^{-1}$. A calibration range of 0.1 to $25 \mathrm{mg} \mathrm{L}^{-1}$ was freshly prepared by diluting the stock solution with distilled water.

\subsubsection{Test Solutions}

One gram $(1.000 \mathrm{~g})$ of yoghurt was weighed into a 250 $\mathrm{mL}$ volumetric flask. Approximately $200 \mathrm{~mL}$ of distilled water were added and homogenized under magnetic stirring for 10 minutes. The flask was made up to volume with distilled water and homogenized. Tartrazine extraction is then performed by solid liquid partitioning from the freshly prepared solution with a preparative stationary phase which is prepared in the laboratory. The solution obtained is filtered. The first drops are rejected. The filtrate $(10 \mathrm{~mL})$ containing tartrazine is subjected to chromatographic analysis. Duplicate injections were used.

\subsubsection{Validation}

The method was validated according to the criteria developed by the "International Conference of Harmonization" [24]. The parameters evaluated to assess the reliability of the results consist of:

- Linearity of the chromatographic response as a function of analyte concentration from 0.1 to $25 \mathrm{mg} \mathrm{L}^{-1}$.
- Repeatability of the chromatographic analysis of the reference solution at two (2) levels of concentration: $1 \mathrm{mg}$ $\mathrm{L}^{-1}$ and $5 \mathrm{mg} \mathrm{L}^{-1}(\mathrm{n}=6)$;

- Repeatability of chromatographic analysis of a sample of yoghurt $(n=6)$;

- Repeatability of the procedure $(n=6)$;

- Accuracy using the standard additions method. Different amounts of tartrazine (50, 100 and $150 \mathrm{mg} \mathrm{kg}^{-1}$ ) were added to yoghurt samples. The samples with or without the addition were subjected to chromatographic analysis to determine the percent recovery.

- The limits of detection (signal-to-noise ratio of 3) and quantification (signal-to-noise ratio of 10) determined were assessed from serial dilutions of the standard solution of tartrazine $1 \mathrm{mg} \mathrm{L}^{-1}$.

\subsubsection{Statistical Treatment}

The linearity of the response of tartrazine was assessed from a scatter plot. The regression line was determined according to the least squares method. An analysis of variance (ANOVA) was performed to test the statistical significance and the overall slope of the regression line. The accuracy was assessed through the coefficient of variation calculated from the ratio of the standard deviation of the mean of each series of measurements. The level of statistical significance was set at 0.05 .

\section{Results and Discussion}

\subsection{Results}

\subsubsection{Analysis Method}

Tartrazine chromatographic peak was identified at a retention time around 1 minute 20 seconds (Figure 2).
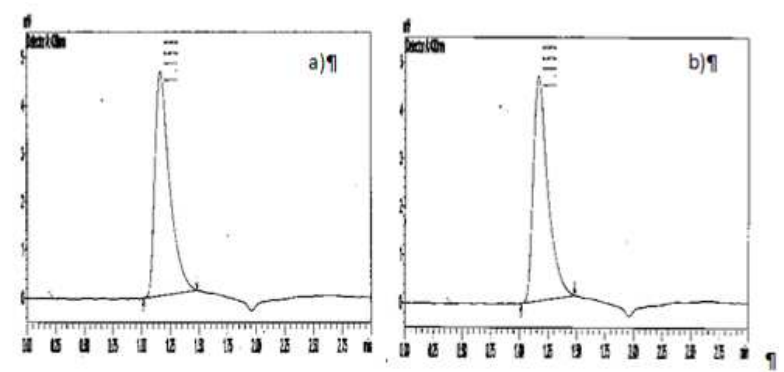

Figure 2. Chromatograms of tartrazine standard solution $0.05 \mathrm{mg} \mathrm{L}^{-1}$ (a) and an extracted of a sample of yoghurt $(b)$.

\subsubsection{Validation}

A linearity range has been set to the concentration range of 0.1 to $25 \mathrm{mg} \mathrm{L}^{-1}$ tartrazine with a coefficient of determination $\mathrm{R}^{2}=0.998$. The line of regression equation was established: $Y=(71871 \pm 7190) X-(23511 \pm 28122)$, $Y$ the chromatographic response and $X$, the concentration in $\mathrm{mg} \mathrm{L}^{-1}$. The repeatability tests reported that relative standard deviations were less than $0.3 \%$ for the reference solutions and at $1.6 \%$ to a yoghurt sample for the chromatographic analysis and $2.7 \%$ for the whole procedure. The average percent recovery of tartrazine was 
$97.6 \%$. The limits of detection and quantification were, respectively, 4.8 and $13.0 \mathrm{mg} \mathrm{kg}^{-1}$.

\subsubsection{Application}

The validated method was applied to control tartrazine levels in yoghurt samples sold in Abidjan markets (Table 1). Tartrazine was not identified in four products (P6, P8, P9 and $\mathrm{P} 15)$. In the other products, tartrazine content's ranged from 51.2 to $709.2 \mathrm{mg} \mathrm{kg}^{-1}$. These levels higher than the admitted norm of $300 \mathrm{mg} \mathrm{kg}^{-1}$ were found in 10 samples, representing $4.8 \%$ of all the analyzed samples. The highest level of tartrazine was $709 \mathrm{mg} \mathrm{kg}^{-1}$ in one yoghurt sample, thus exceeding twice the maximum admitted dose.

Table 1. Tartrazine content in artisanal produced yoghurts.

\begin{tabular}{|c|c|c|c|c|}
\hline Products & $\begin{array}{c}\text { Means (mg } \\
\left.\mathrm{kg}^{-1}\right)\end{array}$ & $\begin{array}{c}\mathrm{s}(\mathrm{mg} \\
\left.\mathrm{kg}^{-1}\right)\end{array}$ & $\begin{array}{c}\min (\mathbf{m g} \\
\left.\mathrm{kg}^{-1}\right)\end{array}$ & $\begin{array}{c}\max (\mathbf{m g} \\
\left.\mathrm{kg}^{-1}\right)\end{array}$ \\
\hline $\begin{array}{l}P 1(n=10), 125 \\
\text { g/sachet }\end{array}$ & 123,8 & 60,0 & 51,2 & 223,1 \\
\hline $\begin{array}{l}\text { P2 }(n=10), 125 \\
\text { g/sachet }\end{array}$ & 246,4 & 60,7 & 161,2 & 330,1 \\
\hline $\begin{array}{l}\text { P3 }(n=10), 125 \\
\text { g/sachet }\end{array}$ & 506,0 & 172,1 & 266,1 & 709,2 \\
\hline $\begin{array}{l}\text { P4 }(n=10), 150 \\
g / \text { sachet }\end{array}$ & 82,8 & 0,11 & 82,1 & 85,4 \\
\hline $\begin{array}{l}\text { P5 }(n=10), 125 \\
\text { g/sachet }\end{array}$ & 90,3 & 0,18 & 85,4 & 92,6 \\
\hline $\begin{array}{l}\text { P6 }(n=10), 100 \\
\text { g/sachet }\end{array}$ & $<\mathrm{LD}$ & - & - & - \\
\hline $\begin{array}{l}\text { P7 }(n=10), 150 \\
\text { g/sachet }\end{array}$ & 89,0 & 0,18 & 86,4 & 90,5 \\
\hline $\begin{array}{l}\text { P8 }(n=10), 100 \\
\text { g/sachet }\end{array}$ & $<\mathrm{LD}$ & - & - & - \\
\hline $\begin{array}{l}\text { P9 }(n=10), 100 \\
\text { g/sachet }\end{array}$ & $<\mathrm{LD}$ & - & - & - \\
\hline $\begin{array}{l}\mathrm{P} 10(\mathrm{n}=10), 150 \\
\mathrm{~g} / \text { sachet }\end{array}$ & 86,5 & 0,28 & 83,1 & 89,4 \\
\hline $\begin{array}{l}\text { P11 }(n=10), 125 \\
\text { g/sachet }\end{array}$ & 81,9 & 0,01 & 81,9 & 82,2 \\
\hline $\begin{array}{l}\mathrm{P} 12(\mathrm{n}=10), 100 \\
\text { g/sachet }\end{array}$ & 82,4 & 0,03 & 82,1 & 83,0 \\
\hline $\begin{array}{l}\mathrm{P} 13(\mathrm{n}=10), 200 \\
\text { g/sachet }\end{array}$ & 86,3 & 0,17 & 84,2 & 87,5 \\
\hline $\begin{array}{l}\mathrm{P} 14(\mathrm{n}=10), 175 \\
\mathrm{~g} / \text { sachet }\end{array}$ & 93,3 & 0,33 & 88,7 & 96,5 \\
\hline $\begin{array}{l}\text { P15 }(n=10), 100 \\
\text { g/sachet }\end{array}$ & $<\mathrm{LD}$ & - & - & - \\
\hline $\begin{array}{l}\text { P16 }(n=10), 125 \\
\text { g/sachet }\end{array}$ & 128,8 & 0,51 & 120,9 & 135,0 \\
\hline $\begin{array}{l}\mathrm{P} 17(\mathrm{n}=10), 150 \\
\text { g/sachet }\end{array}$ & 91,2 & 0,07 & 90,5 & 91,8 \\
\hline $\begin{array}{l}\text { P18 }(n=10), 100 \\
\text { g/sachet }\end{array}$ & 85,5 & 0,02 & 85,3 & 85,7 \\
\hline $\begin{array}{l}\text { P19 }(n=10), 150 \\
\text { g/sachet }\end{array}$ & 98,8 & 0,51 & 94,9 & 109,0 \\
\hline $\begin{array}{l}\text { P20 }(n=10), 125 \\
\text { g/sachet }\end{array}$ & 86,8 & 0,11 & 85,2 & 89,1 \\
\hline $\begin{array}{l}\text { P21 }(n=10), 100 \\
\text { g/sachet }\end{array}$ & 103,7 & 0,15 & 102,4 & 106,6 \\
\hline
\end{tabular}

LD: limit of detection

\subsection{Discussion}

Tartrazine is a polar compound that was rapidly eluted after its pairing with tetrabutylammonium bromide. The operating conditions of LC reverse phase ion-pair defined with the use of an octadecylsilanised stationary phase in a $15 \mathrm{~cm}$ column chromatographic separation were appropriate for a rapid elution of tartrazine. They resulted in a retention time of less than two minutes in isocratic elution mode during the chromatographic analysis. This retention time is similar to the one reported by Kostik and Stafilov on tartrazine analysis by liquid chromatography [17]. It is shorter than those reported by several authors $[12,16,21,22]$. In their study they found a retention time higher than 5 minutes on a $25 \mathrm{~cm}$ column containing a stationary phase bonded silica in isocratic or gradient elution mode.

Satisfactory results of validation tests showed that the method is well suited to the determination of tartrazine in yoghurt sold in Côte d'Ivoire.

The application of the method to the control of levels of tartrazine in yoghurt collected from markets and commercial areas of Abidjan has confirmed the use of tartrazine in yoghurt production. From a quantitative point of view, values above the Codex Alimentarius recommended norm of $300 \mathrm{mg} \mathrm{kg}^{-1}$ were observed in $4.8 \%$ of the analyzed samples. Two essential reasons could explain the high content in tartrazine obtained: i) the desire to make these yoghurts more attractive particularly for young consumers; ii) the lack of knowledge on food dyes and particularly their use in food production. Moreover, these artisanal yoghurts are very often sold around schools and hospitals in Abidjan. Thus, a potential risk of allergic reactions and attention-deficit hyperactivity disorder $[6,25]$ can occur in children who are the most at risk. Literature has already reported a causal link proven between tartrazine and hyperactivity, anxiety and behavior depression in rats by a deficiency of vitamin B6 and zinc [6]. These non- conformities revealed the necessity for a systematic quality control of all yoghurts commercialized in Abidjan, particularly those produced by the artisanal sectors.

\section{Conclusion}

A reliable method for the determination of tartrazine in yoghurt by liquid chromatography after liquid solid extraction has been described in the present study. Higher values than the admitted norm were found in different samples of artisanal yoghurt formulation. This study has highlighted the necessity to systematically monitor levels of tartrazine in yoghurt sold in Côte d'Ivoire.

\section{Acknowledgements}

The laboratory is grateful to Joseph Asket and Marie-Danielle Alloua for their technical contribution. 


\section{References}

[1] N. D. Fortin, Food regulation: law, science, policy, and practice, Hoboken, New Jersey: John Wiley \& Sons, 2011.

[2] European Food Safety Authority, "Re-evaluation of tartrazine (E 102) as a food additive," The EFSA Journal, vol. 7, no. 11, pp. 1331, 2009.

[3] S. Dixit, S. K. Khanna, and M. Das, "All India survey for analyses of colors in sweets and savories: exposure risk in Indian population," J Food Sci., vol. 78, no. 4, pp. T642-7, 2013.

[4] M. S. Ha, S. D. Ha, S. H. Choi and D. H. Bae, "Exposure assessment of synthetic colours approved in Korea," Food Addit Contam Part A Chem Anal Control Expo Risk Assess, vol. 30, no. 4, pp. 643-653, 2013.

[5] S. L. Taylor, S. L. Hefle, and B. J. Gauger, "Food allergies and sensitivities," Food toxicology, W. H. a. C. K. Winter., ed., pp. 2-35, CRC Press, 2010.

[6] M. M. Kamel, and H. S. El-lethey, "The potential health hazard of tartrazine and levels of hyperactivity, anxiety-like symptoms, depression and anti-social behaviour in rats," J. Am. Sci., vol. 7, no. 6, pp. 1211-1218, 2011.

[7] B. De Reynal, and J.-L. Multon, Additifs et auxiliaires de fabrication dans les industries agroalimentaires: Lavoisier, 2009.

[8] B. C. Ojeda, and S. F. Rojas, "Recent applications in derivative ultraviolet/visible absorption spectrophotometry: 2009-2011,” Microchem. J., vol. 106, no. 1-16, 2013.

[9] W. J. Li, Zhou. X., Tong. S.S. and Q. Jia, "Poly(N-isopropylacrylamide-co-N,N'-methylene bisacrylamide) monolithic column embedded with $\gamma$-alumina nanoparticles microextraction coupled with high-performance liquid chromatography for the determination of synthetic food dyes in soft drink samples.," Talanta, vol. 105, pp. 386-392, 2013.

[10] X. Ye, Y. Du, D. Lu and C. Wang, "Fabrication of $\beta$-cyclodextrin-coated poly (diallyldimethylammonium chloride)-functionalized graphene composite film modified glassy carbon-rotating disk electrode and its application for simultaneous electrochemical determination colorants of sunset yellow and tartrazine.," Anal. Chim. Acta., vol. 779, pp. 22-34, 2013.

[11] R. A. Medeiros, B. C. Lourencao, R. C. Rocha-Filho and O. Fatibello-Filho, "Flow injection simultaneous determination of synthetic colorants in food using multiple pulse amperometric detection with a boron-doped diamond electrode.," Talanta, vol. 99, pp. 883-889, 2012.

[12] E. Diacu, and C. Petronela Ene, "Simultaneous determination of tartrazine and sunset yellow in soft drinks by liquid chromatography," Rev. Chim., vol. 60, no. 8, pp. 745-749, 2009.
[13] E. Dinç, A. Hakan Aktaş, D. Baleanu and Ö. Üstündağ, "Simultaneous determination of tartrazine and allura red in commercial preparation by Chemometric HPLC method," J. Food Drug Anal., vol. 14, no. 3, pp. 284-291, 2006.

[14] W. J. Hurst, J. M. McKim, and R. A. Martin, "Determination of tartrazine in food products by HPLC," J. Food Sci., vol. 46, no. 2, pp. 419-420, 1981.

[15] D. P. Wittmer, N. O. Nuessle, and W. G. Haney Jr, "Simultaneous analysis of tartrazine and its intermediates by reversed phase liquid chromatography," Anal. Chem., vol. 47, no. 8 , pp. 1422-23, 1975.

[16] S. Bonan, G. Fedrizzi, S. Menotta and C. Elisabetta, "Simultaneous determination of synthetic dyes in foodstuffs and beverages by high-performance liquid chromatography coupled with diode-array detector," Dyes and Pigments, vol. 99, no. 1, pp. 36-40, 2013.

[17] V. R. Kostik, and T. Stafilov, "XAD-2 HPTLC Method of identification and determination of some synthetic food colourings," Anal. Lett., vol. 28, no. 7, pp. 1305-1316, 1995.

[18] A. V. Schenone, M. J. Culzoni, N. R. Marsili and H. C. Goicoeche, "Determination of tartrazine in beverage samples by stopped-flow analysis and three-way multivariate calibration of non-linear kinetic-spectrophotometric," Food Chem., vol. 138, pp. 1928-1935, 2013.

[19] M. J. Culzoni, A. V. Schenone, N. E. Llamas, M. Garrido, M. S. Di Nezio, B. S. Band and H. C. Goicoechea, "Fast chromatographic method for the determination of dyes in beverages by using high performance liquid chromatography--diode array detection data and second order algorithms," J. Chromatogr. A, vol. 1216, no. 42, pp. 7063-7070, 2009.

[20] J. P. Chaytor, and R. L. Heal, "Separation of synthetic dyes by

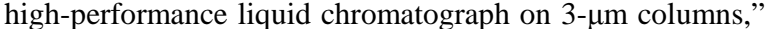
J. Chromatogr. A, vol. 368, no. 450-455, 1986.

[21] K. Ma, Y. N. Yang, X. X. Jiang, M. Zhao, Y. Q. Cai, Simultaneous determination of 20 food additives by high performance liquid chromatography with photo-diode array detector, Chinese Chem. Lett. Vol. 23, pp. 492-495, 2012.

[22] M. Aké, H. Boni, N. Bony, E. Atindéhou and K. A. Malan, "Recherche et détermination de la tartrazine par chromatographie par paire d'ions : application aux limonades commercialisées en Côte d'Ivoire," Ann. Fals. Exp. chim. Toxico., vol. 956, pp. 281-289, 2001.

[23] Z. Li, S. Song, L. Xu, H. Kuang, S. Guo and C. Xu, "Development of an ultrasensitive immunoassay for detecting tartrazine," Sensors, vol. 13, pp. 8155-8169, W. J. Li, Zhou. X., Tong. S.S. and Q. Jia 2013.

[24] Validation of analytical procedures: Text and methodology ICH Standard Topic Q2 (R1), 2005.

[25] L. J. Stevens, K. Thomas, J. R. Burgess, E. Hurt and L. E. Arnold, "Dietary Sensitivities and ADHD Symptoms: Thirty-five Years of Research," Clin. Pediatr., vol. XX, no. X, pp. 1-15, 2010. 